Journal of Contemporary Issues in Business and Government Vol. 27, No. 2,2021

https://cibg.org.au/

P-ISSN: 2204-1990; E-ISSN: 1323-6903

DOI: 10.47750/cibg.2021.27.02.293

\title{
The Dynamic Impact of Crude Oil Price and Real Estate Growth on Stock Market Performance
}

\author{
Josephine Yau Tan Hwang ${ }^{1,2}$, Dayang Siti Salbiah binti Awang Omar ${ }^{1}$, Mubashir \\ Ali Khan ${ }^{1}$, Audrey Liwan ${ }^{1}$ and Jerome Kueh Swee Hui ${ }^{1}$ \\ ${ }^{1}$ Affiliation: Faculty Economics and Business, Universiti Malaysia Sarawak \\ ${ }^{2}$ Coresponding author \\ Contact details \\ Email: ythjosephine@unimas.my \\ Address: Faculty Economics and Business, Universiti Malaysia Sarawak, 94300 Kota \\ Samarahan, Sarawak, Malaysia
}

\section{Acknowledgement}

The authors would like to thank Universiti Malaysia Sarawak (UNIMAS) for the special MyRA Funding with Project ID: F01/SpMYRA/1675/2018.

\section{Abstract:}

This paper examines the effect of crude oil price and real estate growth on Malaysian stock market performance by examining the monthly data from 1999-2016 using both linear and nonlinear tests. These tests examine the long-run and short-run relationship among variables. Granger causality test is used to measure the short-run adjustments towards the long-run relationship among the variables. The results of Granger causality test indicates that a bidirectional relationship exists between stock market performance, crude oil price, real estate. In other words, there is a dynamic relationship among the stock market performance, crude oil and real estate.

Keywords: Crude oil price, real estate, stock market, Malaysia

\section{Introduction}

The stock market performance received considerable attention recently in relation to crude oil price volatility and real estate growth. As stock market is the key to a structural revolution in any economy from a traditional, rigid, insecure bank-based to a more flexible, 